\title{
O PROCESSO CRIATIVO DE ERICO VERISSIMO: APONTAMENTOS EM SUA ESCRITA MEMORIALÍSTICA
}

\author{
Roselene Berbigeier Feil \\ Universidade Federal do Rio Grande do Sul
}

\begin{abstract}
Resumo: Objetiva-se neste trabalho apresentar algumas considerações sobre o processo criativo de Erico Verissimo, algo bastante significativo em sua produção qualificada como "escrita de si", com foco especial em suas obras - Solo de Clarineta vol. I (1995) e Gato Preto em Campo de Neve (1996). Tal iniciativa justifica-se, pois, ainda que Verissimo não tenha, declaradamente, desejado fazer de sua escrita memorialística e de seus relatos de viagem uma explicação técnica acerca do seu modus operandi, tornando, portanto, parte de sua obra uma metaliteratura, é impossível, através da leitura imanente dos textos apontados anteriormente, desvincular um propósito do outro. Para ressaltar esse vínculo, será estabelecido um diálogo entre o corpus escolhido e A Filosofia da Composição (1845) de Edgar Allan Poe, Pós-escrito a O nome da rosa (1985) de Umberto Eco e o Manifesto do surrealismo (1924) de André Breton. Para tal, desenvolver-se-á um percurso que inclui conjecturas sobre a modulação autocrítica de Verissimo, onde o autor intervém, frequentemente, com um comentário pessoal sugerindo um sentido particular para sua escrita e clarificando pontos, considerados por ele, de grande importância. Nesse interim, será mostrado seu procedimento artístico e intelectual, trazendo-se um apanhado geral com suas construções literárias, tendo por meta apontar uma racionalidade e uma objetividade nos elementos mimetizados. Neste sentido, serão pormenorizados, passo a passo, os processos pelos quais o autor escrevia, demonstrando-se a situação de produção do texto, mas, levandose em conta que mapear o processo de criação é algo imaginário, tão imaginário quanto criar, um processo regido por uma força misteriosa impossível de analisar e explicar a contento.
\end{abstract}

Palavras-chave: Erico Verissimo. Processo criativo. Escrita de si. Metaliteratura.

\section{Introdução}

A escrita de Erico Verissimo é expressiva no que se refere à apresentação do próprio processo criativo, bastante comum em seus textos é a explicação técnica a respeito de seu fazer literário, o que não é nenhuma novidade, mas de certa forma o diferencia de muitos dos 
autores de seu tempo que não deixaram explícita nenhuma pormenorização sobre seus métodos. A construção do espaço, das personagens, a escolha das palavras, a interação das personagens com o ambiente e das ações a elas atribuídas, etc. tudo remete a uma composição sistematizada, explicada pelo autor em diversos fragmentos, especialmente naqueles,colhidos de sua escrita memorialística. Talvez o autor não tenha "pensado quão interessante seria um artigo escrito por um autor que quisesse e que pudesse descrever, passo a passo a marcha progressiva seguida em qualquer uma de suas obras até chegar ao término definitivo de sua realização" (POE, 1845, s.p.), tal como pensou Edgar Allan Poe, mas involuntariamente o fez, preenchendo essa lacuna em relação à metaliteratura de sua obra, alvo dos estudos de diversos críticos na atualidade. Os textos memorialísticos de Verissimo se apresentam como metaliteratura, ou seja, uma literatura que se pronuncia sobre si mesma, usando, para tal, todos os elementos literários: metáfora, metonímia, alegoria, etc. É recorrente na sua escrita a criação de algumas alegorias onde expõe seus métodos objetivamente - computador do inconsciente, da boa cozinheira, do Frankenstein, que serão detalhados ao longo desse trabalho. Para Verissimo, “o inconsciente - a que podemos dar também o nome de acaso - é, pois um dos melhores colaboradores do romancista. É preciso confiar nele, contar com ele e... esperar" (VERISSIMO, 1987b, p. 133).

Sua obra memorialística é constituída por metáforas altamente poéticas, neste aspecto, entende-se que esses textos compõem uma poética particular. Sim, uma poética à moda aristotélica, à medida que, ele pensa objetivamente qual o papel do literato na sociedade, qual o papel da literatura, como se elabora a literatura, qual a sua natureza e a sua funcionalidade. Fazendo tudo isso no processo mesmo da escrita e com os materiais da própria escrita - a linguagem -, portanto, são textos que se voltam para si mesmos: sendo autoexplicativos, autorreferenciais e autorreflexivos. Uma das possíveis motivações para essa iniciativa é a preocupação com a crítica não técnica, onde o autor se precavia para minimizar ou, mesmo, eliminar a crítica descritivista, opinativa, positivista e resenhista que não conseguia valorizar os detalhes que julgava merecer maior destaque.

\section{Um (auto)percurso interessantíssimo}

Erico Verissimo parece não ter encontrado nenhuma dificuldade em detalhar seus procedimentos, destacando pontos importantes sobre os mais variados elementos mimetizados 
em sua obra ${ }^{1}$. Uma das características a se apontar está relacionada aos tipos humanos usados em seus romances - a caracterização das personagens era fundamental -, o autor destaca alguns tipos que costumeiramente se apresentavam para fazer parte das tramas: "havia o valentão, o coronel, o peão, o gaudério, o bandido, o poltrão, o paladino, o gaiato, o parlapatão, o capanga, o sisudo, o potoqueiro, o gaúcho da cidade com flor no peito... tantos!"” (VERISSIMO, 1995, p. 291). A criação das personagens é destacada em Galeria Fosca (1987b), "no princípio é o caos - um caos feito de anseios, lembranças, impressões, frustrações, ecos... Desse caos surge uma fisionomia, uma voz, um 'jeito', uma expressão; e quando o autor menos espera, lá está a personagem inteira, falando, movendo-se, vivendo enfim..." (VERISSIMO, 1987b, p. 123) E segue afirmando:

Muita gente me pergunta se costumo inventar as personagens de meus romances ou se as copio da vida real. Ora, até hoje que eu saiba, só um autor criou do nada, e esse foi ninguém mais, ninguém menos que Deus Nosso Senhor, o qual, segundo as Escrituras, levou apenas seis dias para fazer o mundo e tudo quanto nele há de bom e de mau. Depois disso, os outros autores tiveram de contentar-se com a ilusão de que criam, pois na verdade apenas recriam, isto é, usam engenho e memória para modelar seus bonecos à imagem e semelhança das criaturas do Todo-Poderoso.

Nenhum escritor pode afirmar de boa fé que cria do nada. Acho sinceramente que, mesmo quando nos esforçamos para criar uma personagem original que não se pareça com nenhuma outra da vida real ou da literatura, não nos conseguimos livrar das influências principalmente das de nossa vivência. E o perigo dessas influências é tanto maior quando se sabe que no mais das vezes elas não estão no consciente, mas no inconsciente, de onde misteriosamente ditam nossos pensamentos e guiam a mão que escreve. Enquanto isso, nós nos deixamos embriagar pela orgulhosa idéia de que personagens e histórias vão brotando de nosso cérebro, novas como o primeiro homem na manhã da criação, frutos exclusivos de nossa 'capacidade criadora', de nosso 'talento inventivo'.

A verdade, porém, é que ninguém se livra de suas próprias lembranças, nem de velhas idiossincrasias, malquerenças e desejos recalcados. E, quando se trata dum romancista, essas impurezas mais tarde ou mais cedo acabam aparecendo na face ou na alma de suas personagens (VERISSIMO, 1987b, p. 131-132).

Na escrita de Verissimo é de se mencionar, também, a escolha do nome para seus livros, o título é, segundo Umberto Eco, uma chave interpretativa que deve confundir as ideias e jamais discipliná-las, na produção do romancista gaúcho alguns títulos tem nome facilmente associável à história narrada: Saga, Olhai os lírios do campo, Um certo capitão Rodrigo, México, Israel em Abril, etc. Mas porque, por exemplo,Gato Preto em Campo de Neve e Solo de Clarineta? Como surgiram? O que os justifica? O autor esclarece que o surgimento do nome Gato Preto em Campo de Neve se deu quase que espontaneamente numa viagem entre Denver e a Califórnia, durante sua permanência nos Estados Unidos na década de 1950,

\footnotetext{
${ }^{1}$ Por isso, sempre que possível o próprio escritor explicará seus métodos, a voz desta ensaísta será suprimida, dando-se espaço a quem de direito pode enunciar-se.
} 
O céu é dum cinzento esbranquiçado e glacial. Vejo o desfile das casas, das cercas, das árvores mortas... E súbito, um gato preto atravessa correndo um tabuleiro de neve duma brancura imaculada. Fico olhando o quadro fugidio numa fascinação. Sinto que este momento de fria e silenciosa beleza não é gratuito. Um misterioso alguém procurando, dizer-me alguma coisa por meio dessas imagens em negro e branco. Mas quem? Quê? (VERISSIMO, 1996b, p. 415)

No que se refere aos dois volumes de suas memórias, Solo de Clarineta I e II, afirma que os nomes são o resultado de um diálogo consigo mesmo, da alternância e do encaixe de vozes interiores, numa dessas argumentações o nome apareceu:

— Saiu-te uma biografia pífia. Negas?

— Não é sensacional como a vida de Marylin Monroe. Nem aventurosa como a do Papillon. Que é que queres?

- Podias botar mais paixão. Ir mais fundo. Mais sangue.

— Já sei. Querias um striptease completo.

- Isso.

- Sinto muito. Entraste no teatro errado.

- Estou dentro do homem errado. Grito e ninguém me ouve. Sou um prisioneiro. Quantas vezes me castraste. Para quê?

- A porta está aberta. Podes sair quando quiseres.

- Tu dizes isso porque sabes que tal coisa é impossível.

- Querias um concerto de jazz ou uma grande peça sinfônica. Eu te dei um solo de clarineta (VERISSIMO, 1981, p. 323).

O nome para um romance parece, muitas vezes, surgir do inusitado. Umberto Eco, por exemplo, em se tratando de uma de suas mais famosas obras diz, "a ideia de $O$ nome da rosa veio-me quase por acaso e agradou-me porque a rosa é uma figura simbólica, tão densa de significados que quase não tem mais nenhum" (ECO, 1985, p. 9). Além desses interessantes esclarecimentos sobre o nome de suas obras, uma das intervenções mais significativas de Verissimo está relacionada à autocrítica que desenvolve em suas memórias, o autor não se exime de interpretar e de avaliar suas tramas, contrariando a tese de Eco, para quem, o autor deveria morrer depois de escrever, impedindo-se, assim, que este venha a perturbar o caminho do texto. Para Eco, o autor "não deve oferecer interpretações de sua obra, caso contrário não teria escrito um romance, que é uma máquina para gerar interpretações” (ECO, 1985, p. 8) e acrescenta, “o autor não deve interpretar, mas pode contar como e por que escreveu" (ECO, 1985, p. 13). Em síntese, Verissimo desconsidera a primeira parte da teoria de Eco e faz um exame autocrítico, algumas vezes, bastante ácido e ríspido, da maioria de suas obras, contradizendo-se a si mesmo, pois, chegou a afirmar, "se há coisa que não me preocupa nem me ocupa agora é a interpretação dos livros que já escrevi e publiquei” (VERISSIMO, 1996c, p. 123). Em sua ação interpretativa, Verissimo reforça a percepção de Antonio Candido, para quem, "escritor e obra constituem, pois, um par solidário" 
(CANDIDO, 2000, p. 87), onde o leitor sentirá na obra o seu autor, suas ideais e sua visão de mundo, incluindo-se aí as marcas de sua ausência.

Verissimo faz dois tipos de intervenção, uma crítica e outra analítica, a respeito da maioria de seus textos, cita-se o que ele conclui sobre alguns deles:

- Saga (1940) - "que considero o meu pior livro. Esse livro, que revela o estado de espírito do autor naqueles dias sombrios, é um monstro epiceno, símbolo duma absurda ambivalência política [...] tem um final "falso como o resto do livro"” (VERISSIMO, 1995, p. 272).

- Fantoches (1932) - "o livro é de pouca ou nenhuma importância literária" (VERISSIMO, 1996a, prefácio).

- Clarissa (1933) - "por mais ternura que me inspirasse a figura da menina Clarissa, relendo a sua estória eu não a acho satisfatória como literatura. A vida não era apenas uma sucessão de cromos, de momentos de serena poesia doméstica" (VERISSIMO, 1995, p. 255).

- Noite (1932) - "não passou dum exercício literário, sem raízes profundas em problemas pessoais [...] Escrevi-a em menos de dois meses, à beira-mar, em dias geralmente luminosos que eram a negação mesma do espírito da novela" (VERISSIMO, 1995, p. 307).

- Música ao Longe (1934) - "O tema era e é excelente, mas merecia um tratamento menos apressado, superficial e tímido do que lhe dei” (VERISSIMO, 1995, p. 91).

O autor comenta ainda sobre o desenvolvimento a partir de uma ideia central, linha mestre para o romance que lhe deu expressão internacional:

Por ocasião da visita que fiz um dia a um hospital onde um amigo se havia
internado, vi um homem muito jovem sair dum quarto com um bebê recém-nascido
nos braços. Contaram-me que a mãe havia morrido ao dar à luz a criança. A estória
ficou-me na cabeça, revoluteando, provocando idéias e imagens como - hospital...
médicos... mulher que morre... homem que fica, e que provavelmente a amava...
Essa nebulosa foi o núcleo do mundinho de Olhai os Lirios do Campo. Tive a
intuiçãa de que estava na pista dum romance (VERISSIMO, 1995, p. 265).

O trabalho criativo, ou seja, o efeito de mobiliar o universo literário com as coisas do mundo, do mesmo mundo referencial apontado na citação anterior, é destacado por boa parte dos escritores. O problema-chave, para Eco (1985), por exemplo, é construir o mundo até os últimos pormenores, em seguida, as palavras virão quase por si só, isto é, naturalmente. A partir dessa criação do mundo, a história dirá como deve avançar, inclusive as personagens serão forçadas a agir segundo a lei do mundo em que habitam, neste sentido, torna-se excelente o exemplo de Verissimo em se tratando de Olhai os Lírios do Campo: 
Um rapaz pobre que quer conseguir sucesso na vida e segue o atalho dum casamento rico. Será, vejo logo, uma união infeliz. Eugênio deixou para trás a única mulher que o amava de verdade. Olívia. Sim, esse era o nome dela, não sei por que, mas era. Uma enfermeira? Não. Uma médica. Tinham estudado juntos. Imaginei a solenidade da formatura no Teatro São Pedro. Uma noite quente de dezembro. (O perfume dos jasmins da minha infância foi convocado para embalsamar essa noite assinalada na vida de Olívia e Eugênio.) Vi os dois amigos, depois da cerimônia, sentados nos degraus do monumento da praça, à frente do teatro, sem saberem o que fazer com aqueles canudos que lhes davam o direito de exercer a profissão médica (VERISSIMO, 1995, p. 266).

Verissimo ressalta que, muitas vezes, "as ideias para os livros parecem vir no vento. É uma espécie de processo de polinização. Processo misterioso. O ficcionista não deve tentar compreendê-lo. O que deve, isso sim, é evitar a inseminação artificial, pois ela produz livros como o meu romance Saga, o pior de quantos até hoje escrevi” (VERISSIMO, 1995, p. 149). Contudo, há sempre um método por trás da inspiração ou do "processo misterioso", o autor sempre conhece as regras do jogo literário, mesmo que não tenha consciência delas. O autor dizia trabalhar "muitas vezes com um método. Eu tenho o meu. Começo um romance fazendo um roteiro parecido com os de cinema e às vezes chego a desenhar a cara dos personagens" (VERISSIMO, 1996c, p. 59), em nada essa metodologia sistematizada se parece com a teoria de composição surrealista pretendida por André Breton, que fala dos segredos de uma arte mágica,

\begin{abstract}
Mande trazer com que escrever, quando já estiver colocado no lugar mais confortável possível para concentração do seu espírito sobre si mesmo. Ponha-se no estado mais passivo ou receptivo, dos talentos de todos os outros. Pense que a literatura é um dos mais tristes caminhos que levam a tudo. Escreva depressa, sem assunto preconcebido, bastante depressa para não reprimir, e para fugir à tentação de se reler. A primeira frase vem por si, tanto é verdade que a cada segundo há uma frase estranha ao nosso pensamento consciente pedindo para ser exteriorizada. É bastante difícil decidir sobre a frase seguinte: ela participa, sem dúvida, a um só tempo, de nossa atividade consciente e da outra, admitindo-se que o fato de haver escrito a primeira supõe um mínimo de percepção. Isto não lhe importa, aliás; é aí que reside, em maior parte, o interesse do jogo surrealista. [...] Continue enquanto lhe apraz (BRETON, 1924, s.p).
\end{abstract}

Seguindo-se esse anti-método, Eco (1985) frisa que quando um autor diz não ter um método claro, na verdade pretende dizer que trabalha sem pensar em regras elementares para o processo, "quer dizer apenas que trabalhava sem saber que conhecia a regra" (ECO, 1985, p. 14), que a domina metodologicamente. Verissimo sobre as regras destaca, "não costumo pensar com palavras, mas com imagens" (VERISSIMO apud FERNANDES, 1972, p. 2), pensar por imagens implicaria maior liberdade de arranjo, sendo assim as conexões de cenas ou de seres poderia ser feita por cortes, supressões, acréscimos e justaposições. Em sua 
descrição dos processos, Verissimo aponta para a preocupação com a escolha das palavras e da linguagem, afirma ter uma predileção pelas proparoxítonas:

Tenho aprendido alguns nomes de flores, árvores e frutas, menos por espírito de exatidão científica do que pelo prazer de ouvir-lhes o som e apreciar-lhes a forma gráfica. Pensem na beleza de palavras como álamo, nêspera, murta, romã, rosa, nardo, tâmara, nelumbo. Pêssego sugere penugem. Mandrágora tem feitiço. Casuarina, uma conotação de solitude à tardinha. Mística é a mirra. Macia a avelã. Áspero o cardo. Redonda a laranja. Balsâmico o benjoim. Limpa a alfazema. Mágico o gergelim (VERISSIMO, 1987a, p. 108).

Para explicitar os textos a partir da perspectiva do próprio autor, pois conforme Mikhail Bakhtin (1990), só é possível falar da palavra do outro com a ajuda da própria palavra do outro são apontados diversos exemplos da contribuição metaliterária de Verissimo, destacando-se:

1. Quando ele explica sobre a criação de Incidente em Antares, associando esse exemplo ao aspecto cosmológico de que trata Eco (1985):

a primeira coisa que fiz foi um desenho em cores da praça central da cidade, onde a parte mais dramática do romance se desenrola. Depois atendo as personagens ou, melhor, os candidatos a personagens que batiam à minha porta e pediam um lugarzinho no novo romance. A reposta era: 'Entra e senta!' ou então: 'Não tem vaga!' (VERISSIMO apud FERNANDES, 1972, p. 3).

2. Verissimo fala também do desenvolvimento de esboços, em suas memórias, conta como chegava diariamente à criatividade, geralmente, à tarde, escrevendo com três espaços para fazer correções, sem nenhuma secretária, porque não sabia mandar e porque demandava tempo explicar como, o que, etc. Avisa que somente na juventude,

escrevia rapidamente e sem correções. A medida que o tempo foi passando, comecei a escrever a máquina, com três espaços. Faço correções nas entrelinhas e passo outra vez a máquina; reescrevo muitas vezes. Sinto cada vez mais dificuldade com relação ao esboço de um livro, à técnica e tantas outras coisas. Essa é a função do escritor e o preço que ele tem que pagar (VERISSIMO, 1973, p. 76.).

3. Bem como quando trata da ritualização para a escrita:

Trabalhando tenho uma série de manias. Não posso nem pensar em escrever se não estiver com umas calças velhas. Faço um rascunho em papel jornal e depois de corrigir tudo o que escrevi, passo a limpo num papel melhor. Se escrevo de saída num papel bom, tenho a impressão [de] que devo acertar. No papel jornal, faço mil conjecturas, brigo comigo mesmo ('estás burro hoje, hein!'), escrevo-me bilhetes. De vez em quando corto relações com a língua portuguesa, pois às vezes enjôo do meu próprio estilo. Então enveredo pelo inglês, uma língua com que tenho familiaridade. Com isso, posso esquecer a forma e me concentrar na essência: os personagens e a história. Há trechos inteiros de meus pré-originais escritos em inglês. Gosto também de desenhar perfis de gente em meus manuscritos. Outra coisa: escrevo sempre ao som de músicas clássicas (VERISSIMO apud BORDINI, 1995, p. 68). 
4. Ou, quando fala sobre o surgimento dos enredos a partir de referências reais (reiterava que a sua escrita sempre nascia da realidade - O Resto é Silêncio (1943), Poe, em contrapartida, afirmou se tratar de um erro radical construir uma ficção a partir de um incidente do dia a dia, enchendo de descrições, diálogos ou comentários autorais todas as lacunas do fato ou da ação),

vi precipitar-se do alto de um dos edifícios vizinhos um vulto humano, um corpo de mulher, que, ao bater nas pedras do calçamento da rua, produziu um som horrendo que jamais pude esquecer. Crime? Suicídio? Nunca fiquei sabendo ao certo. Mas esse fato, que me impressionou fundamente, um ano mais tarde serviu-me como ponto de partida para o romance (VERISSIMO, 1995, p. 279).

Nos esboços do autor, nota-se principalmente a supressão de palavras, frases, trechos inteiros. Nesses documentos, que não incluem apenas rascunhos propriamente ditos, há ainda farto material roteirístico e páginas de manuscritos, abrangendo pequenas extensões dos vários planos sucessivamente ensaiados e abandonados por ele. Há ainda, além disso, páginas de autossugestões para projetos futuros. Para evidenciar suas teorias criativas e, portanto, reforçar que suas memórias se constituem em uma "poética", Verissimo expõe detalhadamente, suas alegorias, uma das mais interessantes é a do "computador do inconsciente":

Estou convencido de que o inconsciente representa um papel muito importante mais do que o escritor geralmente quer admitir - no ato da criação literária. Costumo comparar nosso inconsciente com um prodigioso computador cuja 'memória' durante os anos de nossa vida (e desconfio que os primeiros dezoito são os mais importantes) vai sendo alimentada, programada com imagens, conhecimentos, vozes, idéias, melodias, impressões de leitura, etc... O 'computador' - à revelia de nossa consciência - começa a 'sortir' todos esses dados, escondendo tão bem alguns deles, que passamos anos e anos sem que tenhamos sequer conhecimento de sua existência. Quando, por exemplo, nos preparamos para escrever um romance e começamos a pensar nas personagens, o 'computador', sensível sempre às nossas necessidades, rompe a mandar-nos 'mensagens', algumas boas - 'pedaços' físicos ou psicológicos de pessoas que conhecemos - outras traiçoeiras - recordações de livros lidos e 'esquecidos' que nos podem levar ao plágio. Cabe ao consciente fazer a seleção, repelir ou aceitar as mensagens do 'computador'. Nada do que nos vem à mente é gratuito. Não é possível nem creio que seja aconselhável tentar criar do nada, esquecer as nossas vivências, obliterar a memória. Muitas vezes leitores me perguntam verbalmente ou por carta se costumo tirar minhas personagens da vida real, isto é, se trabalho d'après nature, fotografando a vida. Minha resposta é negativa. Acho o processo de copiar a vida barato e de certo modo indigno. Lembro-me sempre do conselho sobre a arte de representar que, num romance de Somerset Maugham, um homem do mundo dá a uma atriz: 'Não seja natural: pareça'. Acredito que qualquer homem inteligente pode escrever um romance, que será necessariamente a história de sua própria vida ou da de alguém que ele conhece de maneira íntima. Mas de romancistas sei que não se podem livrar da própria memória. Na minha opinião, o ficcionista legítimo é um tipo de peixe capaz de sobreviver quando fora das águas da autobiografia. Esta idéia não entra absolutamente em conflito com o que escrevi [...] a respeito das figuras 
humanas da vida real que me inspiraram certas personagens de O Tempo e o Vento. $\mathrm{O}$ ficcionista pode usar uma pessoa que conheceu, mas tendo o cuidado de evitar a fotografia servil. É justamente durante esse processo de 'despistamento', ou então no minuto em que o autor resolve criar uma personagem sua, sua mesmo, que o 'computador' insidiosamente começa a mandar-lhe mensagens, e o autor corre o risco de usar esses elementos com orgulho demiúrgico, convencido de que está mesmo criando do nada. Outra coisa: uma vez que o novelista põe de pé uma personagem, esta começa a distanciar-se cada vez mais da criatura da vida real que a sugeriu. Os escritores puramente memorialistas devem achar difícil afastar-se do plano inicial do livro. Traçam para suas figuras um destino irrevogável, ao passo que o romancista verdadeiro - bom ou mau, grande ou pequeno, não importa - esse pode dar-se o luxo de conceder liberdade às suas criaturas. Não se surpreende nem se irrita quando elas recusam dizer as palavras que ele lhes sopra, ou fazer os gestos que ele lhes determina. Muito cedo compreendi que quando uma personagem, por assim dizer, toma o freio nos dentes e dispara, deixando-me para trás, é porque está mesmo viva. Dou-lhe carta de alforria e começo a divertir-me com as surpresas que seu comportamento me proporciona (VERISSIMO, 1995, p. 293-294).

Eco (1985) concorda com esse lado "inconsciente" quando fala da formulação dos problemas para $O$ nome da Rosa, "se eu dissesse que os formulei conscientemente, estaria mentindo" (ECO, 1985, p. 38). Verissimo fala sobre isso e acrescenta,

\begin{abstract}
que o processo de criação literária se opera no plano do inconsciente, repositório insondável de vivências, intuições, experiências... O consciente (que os psicólogos e os analistas me perdoem estas heresias) é apenas a frente da loja, em cujas prateleiras se expõem algumas 'mercadorias' e em cujo balcão monta guarda um sujeito meio atarantado, que olha para a rua e espera a 'freguesia' com a qual terá de se comunicar e transacionar. A parte mais importante da casa é o 'depósito dos fundos', cujo inventário é possível fazer e cujas riquezas ninguém consegue sondar (VERISSIMO apud DE GRANDI, 1971, capa).
\end{abstract}

Daí o manuseio desses elementos mentais do ficcionista ser comparado ao laboratório do Dr. Frankenstein, em que se geram monstros de pedaços de cadáveres, "no fundo, as histórias que escrevemos são verdadeiros monstros feitos de pedaços de recordações, de velhas experiências, influências de leituras, lembranças de pessoas e coisas vistas. Tudo isso misturado dá o romance. E, bem como na história de Frankenstein, o monstro acaba dominando e matando o seu criador" (VERISSIMO apud BORDINI, 1995, p. 51). Assim como os livros que falam sempre de outros livros e as histórias que contam uma história já contada é a fusão da metade imaginação com a metade da experiência vivida que se torna o pano de fundo para os romances. Outra metáfora é a da boa cozinheira, onde substitui o laboratório pela cozinha, "uma cozinheira de talento faz um bom jantar com as sobras do almoço. Comigo é assim" (VERISSIMO apud FERNANDES, 1972, p. 3). Sobre intertextos afirma, tal como fez Eco, "os livros falam sempre de outros livros e toda história conta uma história já contada" (ECO, 1985, p. 20):

o romance que eu ainda não escrevi já existe nos outros, em todos aqueles que vão ler. [...] Muito do que fazemos [...] está fora do papel [...] É mais do que a palavra 
escrita, a combinação de sons, de imagens. Os outros completam... ou desfiguram o que a gente faz. E mesmo o mais egocêntrico dos artistas sempre tem em vista, consciente ou inconscientemente, os outros. Dum certo modo, ele é os outros (VERISSIMO apud BORDINI, 1995, p. 211).

Na sua escrita, outros aspectos destacáveis são:

- A circunscrição fechada do espaço, a moldura à moda de Poe e ao labirinto pensado pelo Eco que destacou “escrever um romance é um fato cosmológico" (ECO, 1985, p. 20), onde o espaço do representado é sempre diferente do espaço da representação. Para Verissimo, as objetividades espaciais são diferentes das reais, sobre isso diz que o sobrado dos Terra-Cambará não deve ser confundido com o sobrado do seu avô materno, nem que Cruz Alta deve ser confundida com Santa Fé. As cidades da sua ficção são construções que não se relacionam com a realidade, tanto que nenhuma das narrativas ficcionais de Verissimo se passa em Cruz Alta, sua terra natal. Para ambientar suas histórias, o autor preferiu criar cidades imaginárias: Antares (Incidente em Antares), Santa Fé (O Tempo e o Vento), Jacareacanga (Música ao Longe), Cerro Hermoso (capital da República de Sacramento em $O$ Senhor Embaixador), Santa Margarida (Olhai os Lírios do Campo), Serra (Música ao Longe), entre outras.

- Verissimo calculava a extensão de seus textos, contudo, a trilogia O Tempo e o Vento que deveria caber em 800 páginas, supera 2.200 páginas, chamado por ele de um "romancerio" que contrariava a tendência da década de 1930, onde a vida batia "recordes de velocidade". Eco (1985) destacou sobre a quantidade de escritos que acumulou na fase de "configuração" de O nome da Rosa, "eu tinha dezenas e dezenas de fichas com todos os textos, às vezes páginas de livros e inúmeras fotocópias, muito mais do que usei [...] enquanto escrevia, tinha ao meu lado todos os textos, espalhados em desordem e lançava os olhos ora sobre um ora sobre outro, copiando um trecho, ligando-o em seguida com outro" (ECO, 1985, p. 38-39). Nesta mesma linha de pensamento sobre seu fazer literário, Verissimo menciona o tempo que levou para concluir sua obra máxima,

Trabalhei em $O$ Continente durante boa parte de 1947 e 1948, e um dia me surpreendi diante duma pilha assustadora de papéis datilografados, e compreendi, vagamente apreensivo, que me seria impossível meter toda a história dos TerraCambará e de Santa Fé dentro dum único volume. Seria necessário um segundo tomo. Quando mais tarde me atirei ao trabalho dessa seqüência foi para verificar que, se quisesse chegar até 1945, precisaria ainda de um terceiro volume. Uma trilogia então? Que fosse! (VERISSIMO, 1995, p. 301).

- Assim como Eco pesquisou sobre a Idade Medieval, Verissimo o fez em relação à história do Rio Grande do Sul, sobretudo, para a construção de O Tempo e o Vento, 
desenvolvendo uma pesquisa bastante detalhada, com dados para o cenário histórico, político, econômico, antropológico e ideológico, e para após, fazer um estudo detido das personagens, através da caracterização do temperamento e do físico, em geral, unida às condutas típicas de seu meio. Reescrevendo a história do Rio Grande do Sul com outras tonalidades, acontecimentos e personagens inventadas, dizendo coisas que os livros de história nunca disseram, ou puderam dizer, com tanta clareza. Eco (1985) avisa sobre a função dessas pesquisas, "em um romance histórico [...] narra-se também para esclarecer melhor para nós, contemporâneos, não só o que aconteceu, mas também em que sentido o que aconteceu ainda conta para nós" (ECO, 1985, p. 34).

- Em relação à construção das personagens femininas Verissimo informa que:

\begin{abstract}
Na criação de Ana terra, até certo ponto me constrangi. Ao criar Clarissa traduzi para o sexo feminino minhas experiências de adolescente. Usei também observações que fiz de meninas adolescentes que conheci. Olívia é um tipo construído. Não se parece com ninguém que conheça. Em Bibiana e Maria Valéria vali-me de meu convívio com velhas, remotas tias, procurando meter-me na pele delas, sem o menor constrangimento. Fernanda é mais uma idéia do que uma pessoa (VERISSIMO, 1995, p. 146).
\end{abstract}

- Sobre a idealização e construção do Capitão Rodrigo Cambará - essa personagem apareceu na mente do autor como alguém que se apresenta numa relação face-a-face, um homem inteiramente constituído, tanto físico quanto emocionalmente: "Desde o momento em que vi o capitão em meus pensamentos, com um corpo, um nome e já com certas tendências ou ímpetos, esse homem passou a existir. E como estava vivo e tinha um temperamento fogoso, a primeira coisa que fez foi livrar-se de seu criador. Quem sou eu para sujeitar um potro como o Capitão Cambará?” (VERISSIMO, 1995, p. 297).

Avisa que o Capitão Rodrigo nasceu com uma missão, ser uma espécie de Erico Verissimo às avessas, "deleguei a Rodrigo procuração para fazer por mim tudo quanto desejei ter feito na vida, mas não fiz por timidez ou falta de coragem moral ou física, é uma explicação não apenas simplista mas simplória” (VERISSIMO, 1995, p. 297). Foi acusado, por alguns leitores, de "assassinar o capitão Rodrigo" por ter inveja dele. Em se tratando da morte das personagens Verissimo afirmou ter dificuldade para se livrar de algumas delas, é o caso do Dr. Seixas, personagem em três romances: Um lugar ao sol, Olhai os Lírios do Campo e Saga, "o diabo do Dr. Seixas principiava a ser um problema. Contratado para entrar naquela casa, dar uma injeção no paciente e ir-se em paz, ele fincava pé, impunha-se como personagem, 'roubava' a cena, desobedecia a seu criador" (VERISSIMO, 1987b, p. 127). Dr. Seixas é um típico personagem que adquire vida e luta por ela a ponto de desafiar o autor. Por 
isso, Verissimo procurando analisar os motivos e as razões que o levaram a matá-lo diz “cheguei à deprimente conclusão de que tudo foi motivado pelo despeito. Uma sórdida, mesquinha vingança de autor. Ferido no meu orgulho de criador, eliminei do mundo dos vivos uma criatura que se recusava a me obedecer. Sou um miserável. Deus tenha piedade de minha alma!” (VERISSIMO, 1987b, p. 129). Mas, teria pelos mesmos propósitos matado o Capitão Rodrigo Cambará? Pergunta que não quer calar.

Dentro da sua "escrita de si" o autor faz uma configuração de si, uma configuração que apresenta o sujeito Erico Verissimo na condição de literato, elege uma personalidade que o justifica enquanto autor preocupado com a linguagem, pois, "não há homens que morrem e matam por causa das palavras dispostas numa frase?" (VERISSIMO apud RODRIGUES, 1965, p. 5). Ou, "por causa de palavras ou frases matamos ou morremos, sentimo-nos desgraçados ou infernizamos a vida de nossos semelhantes" (VERISSIMO, 1981, p. 311). Para o autor, algumas vezes as palavras erguem obstáculos à sua necessidade primária de comunicação, pois, elas "têm tamanha força, que as regras de seu jogo (inventadas por nós mesmos, e nisso está a ironia da coisa toda) são capazes de engendrar verdadeiras camisas-deforça para as ideias e os sentimentos. Se não tomarmos cuidado, a linguagem acaba comandando nossos pensamentos e nossas vidas, tornando quase impossível a comunicação entre as criaturas humanas" (VERISSIMO apud BORDINI, 1995, p. 243).

Verissimo fala ainda de sua opção pelo simples e diz não ter namoros com o barroco ou o rococó literários: "não tenho talentos para inventar uma nova língua nem mesmo expressões novas dentro de nossa língua. Detesto hieróglifos, logogrifos e enigmas pitorescos, quando se trata de literatura" (VERISSIMO, 1996c, p. 22). Destaca que, assim como para Poe, é importante a questão do caráter da palavra,“o enigma da vida é já tão complicado, que o escritor não deve criar em torno dele outro enigma, nem mesmo de natureza verbal" (VERISSIMO, 1981, p. 309). Também se revela preocupado com o tipo de leitor que vai receber sua obra, não visava os leitores cultos ou sofisticados, apesar de ter consciência que, enquanto autores "nós que fazemos ficção conhecemos bem [...] todos os truques para aliciar o leitor" (VERISSIMO, 1987b, p. 120). Eco (1985) afirma que escrever é construir, através do texto, um "modelo específico" de leitor "assim como o pintor pinta pensando no observador do quadro" (ECO, 1985, p. 40), ao contrário de Verissimo que diz, recusando-se ao modelo específico: "quero me comunicar com o maior número possível de leitores, dentro dos limites da dignidade literária" (VERISSIMO, 1996c, p. 22). Em se tratando de crítica literária, para evidenciar a importância dos leitores em detrimento da opinião dos críticos afirmou, "há 
certos romances $[\ldots]$ em torno dos quais mais vale a opinião do leitor leigo e simples que a do intelectual, a do crítico e do técnico de ficção" (VERISSIMO, 1987b, p. 118). Em certa medida, respondia à crítica que o qualificava como simplista, dizendo que, "alguns críticos da minha terra votam um certo desprezo por quem escreve com clareza. Tem uma tendência de associar a idéia de limpidez à de superficialidade" (VERISSIMO, 1996b, p. 333), contra esses argumentos se apoiava na opinião do amigo Monteiro Lobato, "Seu Erico, o escritor de verdade escreve naturalmente como quem mija. Não vá muito atrás dessas novidades que andam por aí e que na maioria dos casos não passam de truques inventados por quem não sabe contar estórias" (VERISSIMO, 1995, p. 161).

Revela-se preocupado com a função do romancista, ou seja, "que o leitor aprenda algo sobre o mundo ou algo sobre a linguagem" (ECO, 1985, p. 48), isto porque, segundo Verissimo:

Desde que comecei a escrever romances, tem-me animado até hoje a idéia de que o menos que um escritor pode fazer, numa época de atrocidades e injustiças como a nossa, é acender a sua lâmpada, fazer luz sobre a realidade de seu mundo, evitando que sobre ele caia a escuridão, propícia aos ladrões, aos assassinos e aos tiranos. Sim, segurar a lâmpada, a despeito da náusea e do horror. Se não tivermos uma lâmpada elétrica, acendamos o nosso toco de vela ou, em último caso, risquemos fósforos repetidamente, como um sinal de que não desertamos nosso posto (VERISSIMO, 1995, p. 45)

Em tudo o que foi apontado, nota-se que existe uma diferença entre a configuração do autor e a configuração do personagem, analisando a construção da persona autobiográfica que é diferente da persona ficcional, porque no caso especial de Verissimo para além de se configurar de maneira a provocar um efeito no leitor, considerando que trata-se de uma poética, ele configura em última instância a persona de um literato, com todas as suas atribuições. Esse sujeito-autor deve ser entendido como uma construção poética dentro do domínio da "escrita de si" onde se coloca em relação aos seus interlocutores e aos críticos de determinadas maneiras, sempre prevendo e antecipando os atos responsivos abordados por Bakhtin (1990). Focando-se nessa persona autobiográfica é possível conhecer a sua relação com a crítica e com os leitores, de maneira a confirmar sua visão, “eu moldei a minha própria imagem, a face do homem que eu desejo que os outros vejam" (VERISSIMO, 1996b, p. 20). No processo de criação de suas obras memorialísticas, Verissimo desloca-se, em parte, do papel de homem, pois poderia falar apenas de suas experiências pessoais, para o de autor que fala do seu método, e após para o de crítico e de analista de sua produção, apesar de não querer fazer a exegese de seus escritos, ele acaba fazendo um percurso autoexplicativo, tanto que afirma que só pode fazer a sua cronologia pessoal em função dos livros que escreveu e de 
como os escreveu. Isto é, mais do que falar sobre um personagem si-mesmo, ele fala de como é/era o seu fazer.

\section{(In)conclusões}

Pode-se observar que Verissimo, na medida em que investiga e apresenta o seu próprio ser e suas motivações existenciais, mergulha nos mistérios da arte como formadora das pessoas que a buscam e a praticam. Em suma, a obra de Verissimo, quer de modo direto quer de modo indireto, fala de si e dos seus valores pessoais, artísticos e existenciais. Em tudo o que produziu, predomina a imaginação criadora, daí seus livros memorialísticos terem aparência de romances e, seus romances terem tons memorialísticos. A leitura da "escrita de si" de Verissimo suscita alguns problemas-chave, seus textos chamam a atenção para o fato de o escritor fazer das suas memórias um longo ensaio autocrítico, tanto para apreciação de suas obras quanto de sua personalidade e de seu comportamento, com os outros e consigo mesmo, mostrando-se, desde a infância, como um indivíduo bastante preocupado com a imagem que o outro terá de si, apesar de o próprio autor admitir ser "muito perigoso um homem levar-se demasiadamente a sério" (VERISSIMO, 1995, p. 322).

\section{Referências}

BAKHTIN, Mikhail. Questões de literatura e estética: a teoria do romance. 2. Ed. São Paulo: Ed. UNESP/Hucitec, 1990.

BORDINI, Maria da G. Criação Literária em Erico Verissimo. Porto Alegre: L\&PM/EDIPUCRS, 1995.

BRETON, André. Manifesto do surrealismo (1924). Disponível em: $<$ http://www.culturabrasil.org/breton.htm>. Acesso em: 11 maio 2011.

CANDIDO, Antonio. Literatura e sociedade: estudos de teoria e história literária. 8. ed. 1. reimp. São Paulo: T. A. Queiróz, 2000.

DE GRANDI, Celito. Somos todos uns mentirosos. Correio da Manhã, Rio de Janeiro, 19 nov. 1971, capa. Entrevista.

ECO, Umberto. Pós-escrito a O nome da rosa. Rio de Janeiro: Nova Fronteira, 1985.

FERNANDES, Carlos M. Verissimo: evite o espelho mágico. O Estado de São Paulo, São Paulo, 12 mar. 1972. p. 2-7. Suplemento Literário.

POE, Edgar A. A Filosofia da Composição (1845). Disponível em: $<$ http://www.scribd.com/doc/37449422/A-Filosofia-da-Composicao-Edgar-Alan-Poe>. Acesso em: 13 abr. 2011. 
RODRIGUES, José M. Deveríamos ter com mais frequência escritores portugueses no Brasil. Voz de Portugal, Lisboa, 9 mai. 1965. Reportagem e entrevista.

VERISSIMO, Erico. Solo de Clarineta. Memórias. Vol. I. 20. Ed. São Paulo: Globo, 1995.

Solo de Clarineta. Vol. 2. 5. Ed. Porto Alegre: Globo, 1981.

Gato preto em campo de neve. 22. Ed. São Paulo: Globo, 1996 b.

Fantoches e outros contos. 13 Ed. São Paulo: Globo, 1996a.

. Israel em Abril. 9. Ed. São Paulo: Globo, 1987a.

. Galeria Fosca. Pesq. e Org. Cristina Penz. Rio de Janeiro: Globo, 1987 b.

A liberdade de escrever: entrevistas sobre literatura e política. Org. Maria da Glória Bordini. Porto Alegre: UFRGS/EDIPUCRS, 1996c.

Ainda não escrevi o livro dos meus sonhos. Manchete. Rio de Janeiro, 1973, p. 76-79. Entrevista.

[Recebido em novembro de 2011 e aceito para publicação em junho de 2012]

\section{The creative process of Erico Verissimo: notes written in your memorial}

Abstract: The objective of this paper is to present some considerations about the creative process from Erico Verissimo, something very significant in its production described as "writing itself", with special focus on his works - Solo Clarinet vol. I (1995) and Black Cat in Field of Snow (1996). This initiative is justified because, although not Verissimo, reportedly wanted to do his writing his memoirs and travel accounts a technical explanation about their modus operandi, making thus a part of his work metaliterature, it is impossible, through the reading of texts immanent previously mentioned, to unlink a purpose other. To emphasize this relationship, a dialogue is established between the chosen corpus and The Philosophy of Composition (1845) Edgar Allan Poe, Postscript to The Name of the Rose (1985) by Umberto Eco and the Manifesto of Surrealism (1924) by André Breton. To this end, it will develop a route that includes conjectures on the modulation of criticism Verissimo, where the author intervenes, often with a personal comment suggesting a particular direction for his writing and clarifying points, which he considered of great importance. In the meantime, your procedure will be shown artistic and intellectual, bringing to an overview of your literary constructions, having as a target point in the rationality and objectivity mimicked elements. In this sense, will be detailed, step by step, the processes by which the author wrote, demonstrating the production situation of the text, but, taking into account that the process of map creation is something imaginary, as imaginary as create, a process governed by a mysterious force impossible to analyze and explain satisfactorily.

Keywords: Erico Verissimo. Creative process. Writing of himself. Metaliterature.

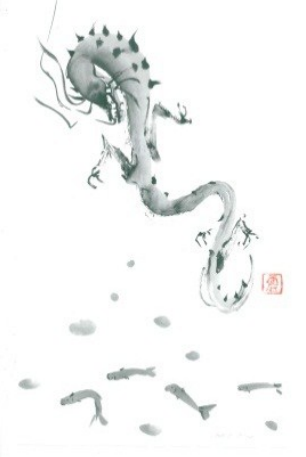

